\section{A rare case of extramedullary hematopoiesis in the mediastinum diagnosed by endoscopic ultrasound}
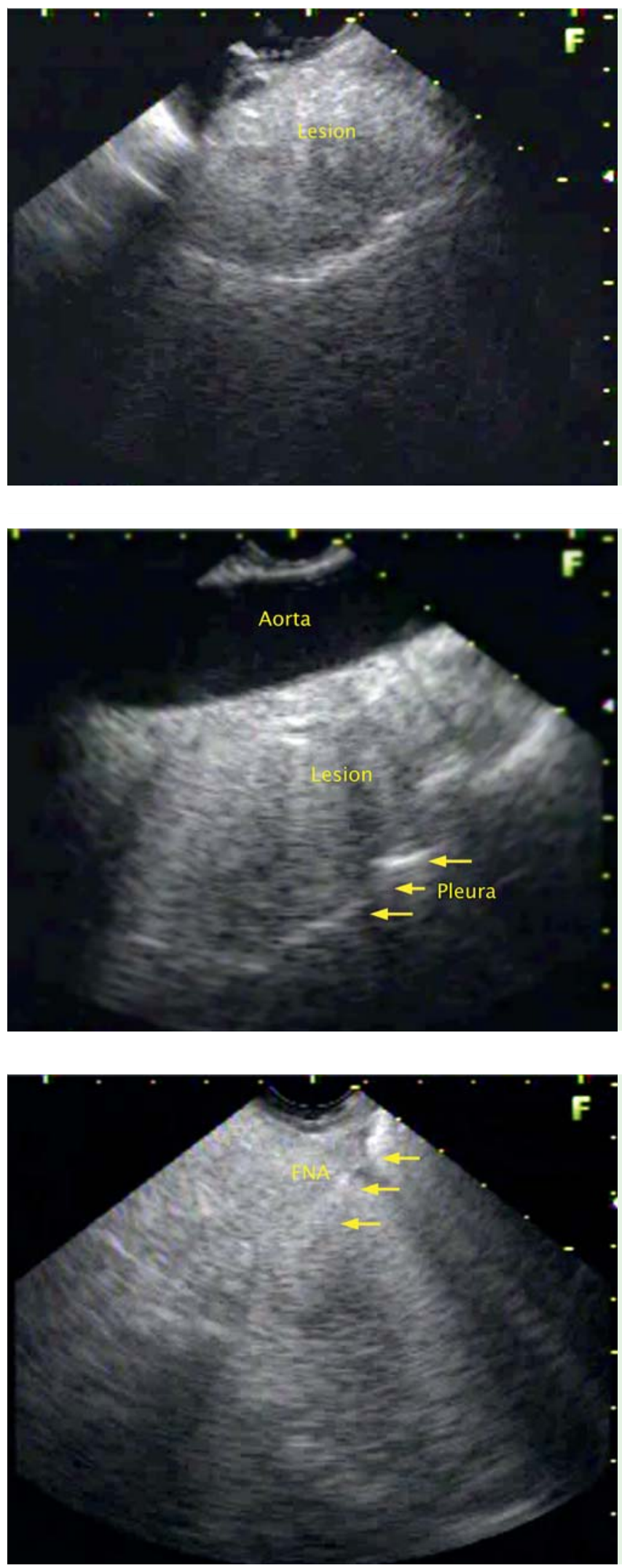

Fig. 1 Endoscopic ultrasound showing a right-sided peri-esophageal, supra-diaphragmatic lesion in a patient with extramedullary

hematopoiesis. Note the hyperechogenic appearance of the lesion.

Fig. 2 Endoscopic ultrasound showing a peri-aortic/vertebral lesion. Note the preserved cleavage plane between the lesion and the pleura.

Fig. 3 Endoscopic ultrasound-guided fine-needle aspiration of the right-sided supra-diaphragmatic lesion. FNA, fine-needle aspiration.
A 48-year-old woman with chest pain for the preceding 2 months and a previous history of hereditary spherocytosis was referred for endoscopic ultrasound (EUS) to evaluate mediastinal lymphadenopathy and a heterogeneous mediastinal mass diagnosed by computed tomography (CT). EUS (Fujinon, Saitama City, Japan) showed a hyperechogenic and heterogeneous peri-esophageal, supra-diaphragmatic lesion ( $\bullet$ Fig. 1) and a peri-aortic/ vertebral lesion ( $\bullet$ Fig.2). EUS also demonstrated multiple lymph nodes in the para-esophageal, subcarinal, and right high paratracheal regions, suggesting a reactive process. The patient underwent EUS-guided fine-needle aspiration (EUSFNA) of the right supra-diaphragmatic lesion, performed with a 19-gauge needle (Cook Medical, Limerick, Ireland) $(\bullet$ Fig. 3). Analysis of the histologic sections confirmed the diagnosis of extramedullary hematopoiesis in the mediastinum ( $\bullet$ Fig.4).

Extramedullary hematopoiesis, the formation of apparently normal blood cells outside the confines of the bone marrow, is a rare condition that is usually associated with a hematologic disorder. It generally occurs in the postero-inferior mediastinum $[1,2]$, frequently involving the liver, spleen, and lymph nodes. However, the condition may also develop in other sites, such as the thymus, kidneys, retroperitoneum, intrathoracic cavity, pleurae, pericardium, and intracranial cavity. Most cases are associated with a hemoglobinopathy that produces severe, chronic anemia, such as thalassemia, hereditary spherocytosis, or hemolytic anemia, or with leukemia, lymphoma, or a myeloproliferative disorder. The differential diagnosis includes neoplastic, infectious, and hereditary or acquired conditions. Magnetic resonance imaging and CT cannot differentiate benign from malignant disease, so invasive procedures are undertaken (trans-thoracic needle biopsy, mediastinoscopy, and thoracoscopy) to establish the diagnosis [3,4]. Recently, EUS has been used in the staging of lung cancer because material can be obtained from mediastinal lymph nodes with a minimally invasive technique (EUS-FNA) [5-8]. In this article, we report a rare case of extramedullary hematopoiesis in the mediastinum diagnosed by EUS-FNA. The procedure is a highly accurate and useful tool for the assessment of mediastinal pathology and should be used to sample tissue from mediastinal lymph nodes or masses adjacent to the esophagus. 


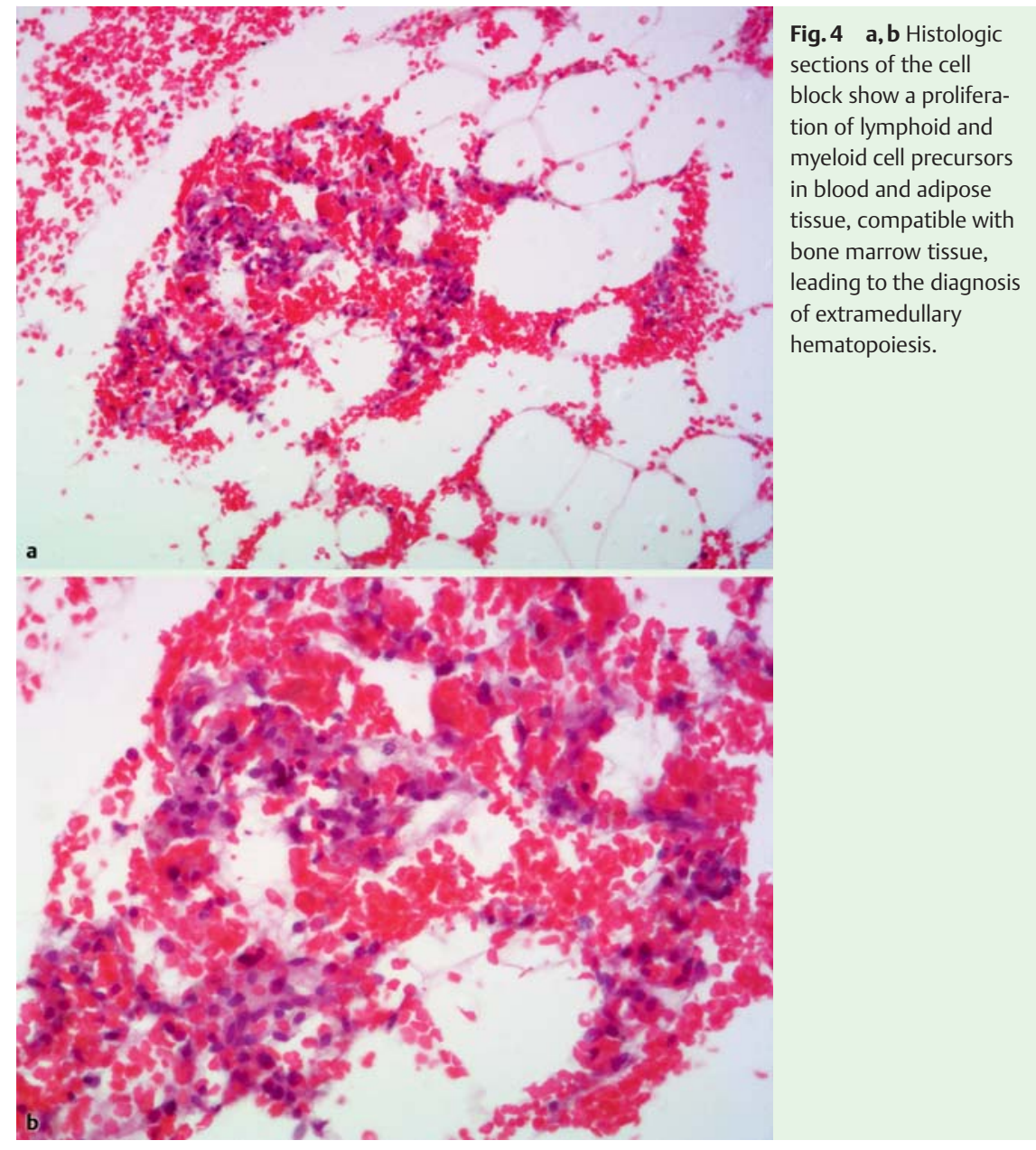

Endoscopy_UCTN_Code_CCL_1AF_2AC

Competing interests: None
Marco Camunha', Augusto Carbonari ${ }^{1}$, Julia Araujo ${ }^{1}$, Ivan Rondelli², Mauro Ajaj Saieg ${ }^{2}$, Lucio Rossini ${ }^{1}$

1 Santa Casa de São Paulo Hospital, Department of Endoscopy, and FrenchBrazilian Centre of Endoscopic Ultrasound (CFBEUS), São Paulo, Brazil

2 Santa Casa de São Paulo Hospital, Department of Cytopathology, São Paulo, Brazil

\section{References}

1 Policarpio-Nicolas ML, Bregman SG, Ihsan M et al. Mass-forming extramedullary hematopoiesis diagnosed by fine-needle aspiration cytology. Diagn Cytopathol 2006; 34: 807-811

2 Castelli $R$, Graziadei G, Karimi M et al. Intrathoracic masses due to extramedullary hematopoiesis. Am J Med Sci 2004; 328: 299-303

3 Lemaire A, Nikolic I, Petersen T et al. Nineyear single center experience with cervical mediastinoscopy: complications and false negative rate. Ann Thorac Surg 2006; 82: 1185-1189, discussion 1189-1190

4 Mentzer SJ, Swanson SJ, DeCamp MM et al. Mediastinoscopy, thoracoscopy, and videoassisted thoracic surgery in the diagnosis and staging of lung cancer [review]. Chest 1997; 112: 239S - 241S

5 Buscarini E, De Angelis C, Arcidiacono PG et al. Multicentre retrospective study on endoscopic ultrasound complications. Dig Liver Dis 2006; 38: $762-767$

6 Nguyen TQ Kalade A, Prasad S et al. Endoscopic ultrasound guided fine needle aspiration (EUS-FNA) of mediastinal lesions. ANZ J Surg 2011; 81: 75-78

7 Wang KX, Ben QW, Jin ZD et al. Assessment of morbidity and mortality associated with EUS-guided FNA: a systematic review. Gastrointest Endosc 2011; 73: 283 -290

8 Larsen SS, Krasnik M, Vilmann P et al. Endoscopic ultrasound guided biopsy of mediastinal lesions has a major impact on patient management. Thorax 2002; 57: 98 - 103

Bibliography

DOI http://dx.doi.org/

10.1055/s-0034-1391335

Endoscopy 2015; 47: E119-E120

(c) Georg Thieme Verlag KG

Stuttgart . New York

ISSN 0013-726X

\section{Corresponding author}

Augusto Carbonari

Santa Casa de São Paulo Hospital

Department of Endoscopy

French-Brazilian Centre of Endoscopic Ultrasound

(CFBEUS)

Rua Cesário Mota junior, 112

São Paulo 01221-020

Brazil

Fax: +55-11-21767000

augustocarbonari@gmail.com 